\title{
Patient-derived xenografts of triple-negative breast cancer reproduce molecular features of patient tumors and respond to mTOR inhibition
}

Haiyu Zhang ${ }^{1 \dagger}$, Adam L Cohen ${ }^{2 \dagger}$, Sujatha Krishnakumar ${ }^{3}$, Irene L Wapnir ${ }^{1}$, Selvaraju Veeriah ${ }^{4}$, Glenn Deng ${ }^{1,5}$, Marc A Coram ${ }^{6}$, Caroline M Piskun ${ }^{1,7}$, Teri A Longacre ${ }^{8}$, Michael Herrler ${ }^{9}$, Daniel O Frimannsson ${ }^{1,10}$, Melinda L Telli ${ }^{11}$, Frederick M Dirbas ${ }^{1}$, AC Matin ${ }^{10}$, Shanaz H Dairkee ${ }^{1,12}$, Banafshe Larijani ${ }^{4}$, Gennadi V Glinsky ${ }^{1,13}$, Andrea H Bild ${ }^{14^{*}}$ and Stefanie S Jeffrey ${ }^{1 *}$

\begin{abstract}
Introduction: Triple-negative breast cancer (TNBC) is aggressive and lacks targeted therapies. Phosphatidylinositide 3-kinase (PI3K)/mammalian target of rapamycin (MTOR) pathways are frequently activated in TNBC patient tumors at the genome, gene expression and protein levels, and mTOR inhibitors have been shown to inhibit growth in TNBC cell lines. We describe a panel of patient-derived xenografts representing multiple TNBC subtypes and use them to test preclinical drug efficacy of two mTOR inhibitors, sirolimus (rapamycin) and temsirolimus (CCl-779).

Methods: We generated a panel of seven patient-derived orthotopic xenografts from six primary TNBC tumors and one metastasis. Patient tumors and corresponding xenografts were compared by histology, immunohistochemistry, array comparative genomic hybridization (aCGH) and phosphatidylinositol-4,5-bisphosphate 3-kinase, catalytic subunit alpha (PIK3CA) sequencing; TNBC subtypes were determined. Using a previously published logistic regression approach, we generated a rapamycin response signature from Connectivity Map gene expression data and used it to predict rapamycin sensitivity in 1,401 human breast cancers of different intrinsic subtypes, prompting in vivo testing of mTOR inhibitors and doxorubicin in our TNBC xenografts.

Results: Patient-derived xenografts recapitulated histology, biomarker expression and global genomic features of patient tumors. Two primary tumors had PIK3CA coding mutations, and five of six primary tumors showed flanking intron single nucleotide polymorphisms (SNPs) with conservation of sequence variations between primary tumors and xenografts, even on subsequent xenograft passages. Gene expression profiling showed that our models represent at least four of six TNBC subtypes. The rapamycin response signature predicted sensitivity for $94 \%$ of basal-like breast cancers in a large dataset. Drug testing of mTOR inhibitors in our xenografts showed 77 to $99 \%$ growth inhibition, significantly more than doxorubicin; protein phosphorylation studies indicated constitutive activation of the mTOR pathway that decreased with treatment. However, no tumor was completely eradicated.
\end{abstract}

Conclusions: A panel of patient-derived xenograft models covering a spectrum of TNBC subtypes was generated that histologically and genomically matched original patient tumors. Consistent with in silico predictions, mTOR inhibitor testing in our TNBC xenografts showed significant tumor growth inhibition in all, suggesting that mTOR inhibitors can be effective in TNBC, but will require use with additional therapies, warranting investigation of optimal drug combinations.

\footnotetext{
* Correspondence: andreab@genetics.utah.edu; ssj@stanford.edu

${ }^{\dagger}$ Equal contributors

${ }^{14}$ Department of Pharmacology and Toxicology, University of Utah, Salt Lake

City, UT 84112, USA

'Division of Surgical Oncology, Stanford University School of Medicine,

Stanford, CA 94305, USA

Full list of author information is available at the end of the article
} 


\section{Introduction}

Triple-negative breast cancers (TNBCs), which lack expression of estrogen receptor (ER), progesterone receptor (PR) and human epidermal growth factor receptor 2 (HER2), account for approximately 10 to $17 \%$ of all breast cancers [1-3] and are associated with relatively poor clinical outcomes. About 70 to $80 \%$ of TNBCs comprise the basal-like breast cancer (BLBC) intrinsic subtype as defined by gene expression profiling [4-6], although more recently, TNBCs have been further subclassified into six subtypes distinguished by gene ontologies and gene expression patterns $[7,8]$. The lack of targeted therapies for this aggressive breast cancer subtype is a key treatment issue and testing new therapeutic regimens is clinically important.

The mammalian target of rapamycin (mTOR) is a key downstream regulator of the phosphatidylinositide 3-kinase (PI3K) pathway, one of the most commonly activated signaling pathways in cancer $[9,10]$. mTOR exists in two complexes, mTORC1 and mTORC2. mTORC2 is less well understood but has been shown to regulate cell proliferation and cytoskeletal organization $[11,12]$. PI3K/mTORC1 is frequently activated in human cancers by gain-of-function mutations and amplifications of its upstream activators - such as epidermal growth factor receptor (EGFR), HER2 [13], PI3K or protein kinase B (AKT) - and by the loss of its suppressors, such as phosphatase and tensin homologue (PTEN) [14], inositol polyphosphate-4-phosphatase, type II (INPP4B) [15], or the tuberous sclerosis complex (TSC), mediated by the tumor suppressor genes, TSC1 and TSC2 [16,17]. Activated $\mathrm{mTORC1}$, an evolutionarily conserved serine/threonine kinase, will phosphorylate downstream proteins, such as p70 ribosomal S6 kinase 1 (S6K1) [18] and eukaryotic translation initiation factor $4 \mathrm{E}$ binding protein 1 (4EBP1) [19], to regulate protein synthesis, ribosome biogenesis and autophagy that contribute to cell proliferation, differentiation and survival [17,20-22]. Activation of the AKT/ mTOR pathway is a poor prognostic factor for many types of cancers, including breast cancer [23-27].

Rapamycin (sirolimus) is a specific allosteric inhibitor of mTOR and is the active form of rapamycin analogs. The rapamycin analogs CCI-779 (temsirolimus) and RAD001 (everolimus) are approved for the clinical treatment of advanced renal cell carcinoma [28], progressive neuroendocrine tumors of pancreatic origin [29], subependymal giant cell astrocytoma associated with tuberous sclerosis [30], and more recently for postmenopausal women with advanced hormone receptorpositive, HER2-negative breast cancer in combination with the aromatase inhibitor exemestane [31]. Pertinent for other types of breast cancer, increasing lines of evidence indicate that the PI3K/mTOR pathway is activated in TNBCs and/or BLBCs at the genetic, gene expression and protein levels [14,32-37]. mTOR inhibitors show growth inhibition of
TNBC cell lines in both in vitro and in vivo preclinical studies $[14,26,33,38]$. PIK3CA mutations have been shown to be associated with mTOR inhibitor sensitivity in both cell lines and clinical studies [39-41]. mTOR inhibitors are among the therapeutic agents being actively investigated in clinical trials in patients with TNBC [42-44], and recently, a phase II trial evaluating a combination of everolimus and carboplatin showed a clinical benefit rate of $36 \%$ in metastatic TNBC patients [42].

In contrast to previous in vivo preclinical drug testing studies using xenografts derived from established breast cancer cell lines, we were interested in determining preclinical drug efficacy in patient-derived TNBC orthotopic xenograft models generated from human tumors obtained fresh from the operating room. Personalized tumorgraft models, also called "avatars", propagated using patient-derived tumors have shown some success when used to guide clinical treatment in patients with advanced cancer $[45,46]$.

We generated a panel of seven patient-derived orthotopic xenograft models of primary and metastatic TNBC and showed that these models recapitulated histologic and molecular features of the patients' tumors from which they were derived. We used the Connectivity Map, a compendium of genome-wide transcriptional data from cultured human cells treated with bioactive small molecules, to determine a rapamycin response signature. Applying this signature to large breast cancer datasets stratified into intrinsic breast cancer subtypes, we predicted that most BLBCs would show some sensitivity to rapamycin. We then proceeded with in vivo drug testing of two mTOR inhibitors, sirolimus and temsirolimus, in our patient-derived TNBC models, which demonstrated significant growth inhibition by both drugs. However, while growth inhibition was very impressive for all TNBC xenografts, none had complete tumor ablation. Our results strongly support the use of mTOR inhibitors as part of combined therapy for TNBC in preclinical and clinical trials and suggest the need for further investigations into appropriate drug combinations.

\section{Materials and methods}

\section{Establishment of patient-derived orthotopic xenografts}

Both the Stanford University Research Compliance Office's Human Subjects Research and IRB Panel and Stanford's Administrative Panel on Laboratory Animal Care (APLAC) approved this study. After obtaining informed written patient consent, breast cancer tissues were obtained fresh from operating rooms at Stanford Hospital and Clinics. In six cases of TNBC (SUTI097, SUTI103, SUTI110, SUTI151, SUTI319, SUTI368), fresh tumor tissue was sterilely obtained from primary breast cancer tissue that was undergoing surgical excision, and in one case (SUTI151M), the tumor tissue was taken fresh 
from a soft tissue TNBC metastasis to the quadriceps muscle in the thigh that was undergoing biopsy (SUTI151M is from the same patient who had months earlier donated a piece of her primary breast tumor SUTI151). Portions were frozen or placed in formalin and embedded in paraffin for later analyses. Fresh tumor tissue was kept on ice in RPMI 1640 medium supplemented with penicillin/streptomycin and $10 \%$ heat inactivated FBS (Invitrogen-Life Technologies, Carlsbad, CA, USA) for transport, minced into one to two millimeter fragments, then sterilely and orthotopically transplanted into the number two mammary fat pads of 5 to 10 female NOD SCID mice (NOD.CB17-

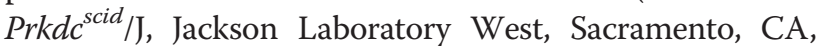
USA). Briefly, the mice were anesthetized by inhalation of 1 to $3 \%$ isoflurane, their hair was clipped, and their skin sterilized with povidone-iodine and alcohol. A small skin incision was made in the lateral flank and minced tumor chunks were mixed with LDEV-free Matrigel (BD Biosciences, San Jose, CA, USA) and implanted into the mammary fat pad by trochar insertion. The incision site was closed with Vetbond tissue adhesive (3 M, St. Paul, MN, USA). Mice were maintained in pathogen-free animal housing. The established xenografts were subsequently passaged from mouse to mouse to expand xenograft numbers; xenograft tumors were also stored frozen in FBS containing 10\% dimethyl sulfoxide (DMSO, EMD Chemicals Inc., Billerica, MA, USA) solution for future engraftment. Xenograft tumor tissue was frozen on dry ice for RNA isolation and microarray analysis and for subsequent protein analyses. Tumor fragments were also fixed in phosphate buffered saline with $10 \%$ formalin (Sigma-Aldrich, St. Louis, MO, USA) for histological studies. All animal care was performed in accordance with Stanford University and IACUC guidelines.

\section{Immunohistochemistry}

Formalin-fixed, paraffin-embedded tissue sections of patient or xenograft tumors were cut into $4 \mu \mathrm{m}$ sections, deparaffinized in xylene, rinsed in ethanol and rehydrated. Staining was performed using the Ventana XT platform and internal antigen retrieval CC1 standard. The antibodies used were rabbit monoclonal antibodies for ER $\alpha$ (clone SP1, 1:25 dilution, Thermo Scientific, Fremont, CA, USA) and PR (clone 1E2, ready to use, Roche-Ventana Medical Systems, Inc., Tucson, AZ, USA). The universal secondary protocol and the DAB MAP kit (Ventana Medical Systems, Inc., Tucson, AZ, USA) were used to detect and amplify the signal. Both biomarkers were scored using a three-tier system: $0=$ negative, $1=$ weak, and $2=$ strong, respectively defined as $<1 \%, 1 \%$ to $50 \%$, and $\geq 50 \%$ of tumor cell nuclei staining positively. HER2 protein expression was performed and interpreted using the Ventana PATHWAY HER2 antibody (rabbit monoclonal, clone 4B5; Ventana,
Tucson, AZ, USA). The Food and Drug Administrationapproved Ventana PATHWAY is scored from 0 to $3+$. Staining in $<10 \%$ of tumor cells is scored as showing no overexpression (0 or $1+)$. Strong, complete, circumferential membrane staining in $>30 \%$ of tumor cells is considered overexpression and is designated as strong positive (3+). Strong circumferential membrane staining in $<30 \%$ of tumor cells, or circumferential but less than strong staining in any proportion of tumor cells, is designated as equivocal $(2+)$. All immunohistochemical assays were conducted in parallel with known positive and negative controls. The slides were observed using a Nikon Eclipse 80i microscope (Nikon Instruments Inc., Melville, NY, USA). Pictures were taken using a Nikon Digital Camera DXM1200F and images were obtained using Nikon ACT-1 software.

\section{Array $\mathrm{CGH}$ and PIK3CA mutation analysis}

Genomic DNA was extracted from patient or xenograft tumor samples using DNeasy Blood \& Tissue Kit (Qiagen, Valencia, CA, USA). Array CGH analyses were performed at SciGene (Sunnyvale, CA, USA) using Human Genome CGH Microarray 4x44K (Agilent Technologies, Santa Clara, CA, USA), and processed on SciGene's robotic aCGH workstations (ArrayPrep ${ }^{\bullet}$ Target Preparation System, Mai Tai Hybridization System, and Little Dipper ${ }^{\circledR}$ Processor, SciGene, Sunnyvale, CA, USA).

Mutations were detected by sequencing PCR products derived from amplification primers in the introns flanking PIK3CA exons 1, 2, 3, 5, 6, 7, 9, 18 and 20 using Ampli Taq Gold DNA polymerase (Applied Biosystems-Life Technologies, Carlsbad, CA, USA). The primer sets used in these reactions are listed in Table S1 in Additional file 1. Exons that had sequence homology with a known PIK3CA pseudogene were not sequenced; however, the sequenced exons included all common mutation hotspots. The reaction was run using a touchdown PCR protocol where the annealing temperature was started at $63^{\circ} \mathrm{C}$ and decreased for $0.5^{\circ} \mathrm{C}$ per cycle for 12 cycles. Then the reaction was continued for another 25 cycles at $94^{\circ} \mathrm{C}, 30 \mathrm{sec} ; 58^{\circ} \mathrm{C}$, $30 \mathrm{sec}$; and $72^{\circ} \mathrm{C}, 30 \mathrm{sec}$ per cycle. PCR products were checked by $2 \%$ agarose gel against a GeneRuler 50 bp DNA Ladder (Frementas, Glen Burnie, MD, USA) and sequenced by BigDye Terminator v3.0 Cycle Sequencing Kits (Applied Biosystems-Life Technologies, Carlsbad, CA, USA). The sequencing results were analyzed with Sequencher 4.8 software (Gene Codes Corporation, Ann Arbor, MI, USA).

\section{Microarray and TNBC subtype analysis}

Frozen tumor tissues from xenografts were cut into small pieces on dry ice. RNA was extracted using RNeasy Plus Mini Kit (Qiagen) following the manufacturer's instructions. The quantity and purity of the RNA sample was measured using the Agilent 2100 bioanalyzer (Agilent Technologies). RNA samples were submitted to 
Stanford Protein and Nucleic Acid core facility for microarray analysis using Affymetrix GeneChip Human Genome U133 Plus 2.0 arrays. All xenograft microarray datasets are posted on GEO under accession number GSE47079 [47].

TNBC subtyping was done following the Pietenpol group's methods $[7,8]$. The microarray data of the patient derived xenograft tumors were robust multi-array average (RMA) normalized and log transformed. For genes containing multiple probes, the probe with the largest interquartile range across the samples was chosen to represent the gene. The processed samples were uploaded to the website [48], where the samples were subjected to an ER-filter scrutiny and then assigned TNBC subtypes.

\section{Generation of an in silico rapamycin response signature}

A rapamycin response signature was generated as described previously [49] using Connectivity Map Build 02 gene expression data of 5 rapamycin treated and 18 control MCF7 cell samples [50]. The Connectivity Map studies highlight the ability to use drug treatment on cell lines to identify a set of genes that reflect response to a drug; therefore, independent of the cell type profiled, a "signature" of drug response can be identified from the data that reflects the response to drug treatment [50]. Multiple studies by other groups and our own have shown that such drug response signatures do also function as drug sensitivity/resistance signatures, with sensitive samples having gene expression patterns more like untreated cells and resistant samples having gene expression patterns more like treated cells [49-52]. Specifically, tumors with dysregulation of genes that are modulated by treatment of rapamycin will be predicted as "sensitive" or "resistant" based on their correlation to gene dysregulation from rapamycin treatment in the Connectivity Map data. This approach, which uses expression data from cell lines before and after treatment with a drug, has the advantage over using expression data from cell lines classified as 'resistant' or 'sensitive' because cell line data have confounding factors, such as subtype that can affect prediction models. By using prediction models that include genes specific to a particular drug's response, we are not limited by these confounding factors. Thus, treated cell lines of one subtype (for example, luminal MCF7 cells) may be used to predict drug response in samples of different subtypes (for example, basal-like or HER2overexpressing cancer cells).

To generate the signature, Mas5 normalized gene expression data were quantile-normalized and log2 transformed and used as the training set. A Bayesian binary regression algorithm was then used on the training set to generate the signature. It was further optimized and internally validated in leave-one-out cross-validation (LOOCV) analysis, which tests each individual sample's classification by leaving it out of the model and predicting if it is treated or untreated $[49,51]$.

\section{Validation and application of the rapamycin response signature}

For signature external validation, CEL files were downloaded from GEO GSE18571, which contains gene expression data for both in vitro and in vivo rapamycin treatment samples on TNBC cell line MDA-MB-468 [26], and from Connectivity Map batches 2, 35, 44, 56, 63, 70, 626, 757 and 767, and analyzed as described by Cohen et al. [49]. We then confirmed the ability of the rapamycin response signature to predict sensitivity to rapamycin in vitro by comparing the EC50 (see below) for a diverse panel of cell lines to the predicted sensitivity, that is, similarity to untreated cells, based on gene expression.

As previously described [49], 18 breast cancer cell lines were obtained from ATCC (HCC38, HCC1806, HCC1428, HCC1143, BT483, BT549, BT474, MDA-MB-361, MDAMB-157, MDA-MB-435S (now considered to be of melanoma origin), MDA-MB-231, MDA-MB-453, SKBR3, ZR75, CAMA I, MCF7, Hs578t, T47D) and used for doseresponse assays. Cells were seeded in 384-well plates (Nunc, Rochester, NY, USA) in MEBM media (Lonza, Walkersville, MD, USA) containing 5\% fetal bovine serum (Gibco, Grand Island, NY, USA), at a density to yield $80 \%$ confluency in control-treated wells at $96 \mathrm{~h}$ post-treatment (as determined by growth curves). After $24 \mathrm{~h}$, rapamycin was added at 10 doses of $0,0.1 \mathrm{pM}, 0.3 \mathrm{pM}, 1 \mathrm{pM}, 3$ pM, 10 pM, 30 pM, 100 pM, 300 pM and 1 nM. A BIOMEK 3000 (Beckman Coulter, Indianapolis, IN, USA) robot was used to seed the cells and dispense the drug. After 96 h, CellTiter-Blue Reagent (Promega, Madison, WI, USA) was added to test cell viability. After $2 \mathrm{~h}$ of incubation at $37^{\circ} \mathrm{C}$, the fluorescence was recorded $\left(560(20)_{\text {Ex }} / 590(10)_{\text {Em }}\right)$ using a Victor3V 1420 Multilabel Counter (Perkin-Elmer, Waltham, MA, USA) plate reader. After subtracting background fluorescence, EC50 was calculated using GraphPad Prism v5 (GraphPad Software, La Jolla, CA, USA) to fit a constrained sigmoidal dose-response curve. Predicted sensitivity for these cell lines was computed using gene expression data from Cohen et al. [49] and applying the Bayesian binary regression model. Detailed methods for running the regression model are given in [53]. Predicted sensitivity was compared to actual EC50 using linear regression.

To examine the relationship between intrinsic subtype and rapamycin sensitivity, 1,401 breast cancer samples from eight microarray studies were then analyzed (Table S2 in Additional file 2, duplicate samples were removed from GEO datasets GSE6532, GSE7390 and GSE3494). Intrinsic breast cancer subtypes were assigned as previously 
described $[49,54,55]$. Rapamycin sensitivity of the patient breast cancer sample was calculated as described by Cohen et al. [49]. A detailed method, the input files, output files and the logistic regression program used in this study are available in [53].

\section{In vivo TNBC xenograft drug treatment experiments}

Rapamycin and CCI-779 (LC Laboratories, Woburn, MA, USA) were stored as $50 \mathrm{mg} / \mathrm{ml}$ solutions in $100 \%$ ethanol at $-80^{\circ} \mathrm{C}$. The stored solutions were diluted in PBS containing 4\% ethanol, 5\% polyethylene glycol 400 and $5 \%$ Tween 80 for treatment. When tumor xenografts grew to an average between 50 to $100 \mathrm{~mm}^{3}$ in tumor volume, mice were stratified and randomized by tumor volume into treatment groups of 5 to 10 mice each. The treatment groups included: 1) rapamycin (sirolimus) group, receiving intraperitoneal (IP) administration of $7.5 \mathrm{mg} / \mathrm{kg}$ rapamycin every other day for up to six weeks; 2) CCI-779 (temsirolimus) group, receiving IP administration of $7.5 \mathrm{mg} / \mathrm{kg}$ of CCI-779 every other day for up to four weeks; 3) control group, receiving IP administration of control vehicle for up to four weeks; and, in some sets of experiments, 4) a doxorubicin group, receiving IP administration of $2 \mathrm{mg} / \mathrm{kg}$ doxorubicin (Sigma-Aldrich, St. Louis, MO, USA) diluted in PBS once every week for three weeks. Tumors were measured twice a week with a caliper in two dimensions. Tumor volume was calculated by the following formula: tumor volume $=\left(l \times w^{2}\right) / 2$, where $l$ is the longest diameter of the tumor, $w$ is the shortest diameter of the tumor. Mean tumor volumes were calculated, and growth curves were established as a function of time. The error bars indicated the value of the standard error of the mean. The Student's $t$-test was used for statistical analysis. We considered $P<0.05$ as statistically significant.

\section{Protein extraction and Western blot analysis}

For protein extraction, frozen xenograft tumors were gently thawed and washed in ice-cold PBS. They were then homogenized using a glass homogenizer and lysed in radio-immunoprecipitation assay buffer containing protease and complete phosphatase inhibitors (Roche, West Sussex, UK). After quantification using Pierce's BCA protein assay (Thermo Scientific Pierce, Leicestershire, UK), 5 to $10 \mu \mathrm{g}$ total proteins were run on 4 to $12 \%$ SDS-PAGE gels (NuPAGE Bis-Tris Gels, Invitrogen-Life Technologies, Paisley, UK), then immunoblotted with the antibodies for PTEN, mTOR, p-mTOR (Ser 2448), 4EBP1, p-4EBP1 (Ser 65), S6K1, p-S6K1 (Thr 389), eIF4E and p-eIF4E (Ser 209) at 1:1,000 dilutions. Secondary horseradish peroxidase (HRP)-labeled antibodies were used at 1:5,000 dilutions. Tubulin was used as a loading control. All antibodies were obtained from Cell
Signaling Technology (Hitchin, Hertfordshire, UK). Membranes were visualized by the ECL developer system (GE Healthcare Life Sciences, Piscataway, NJ, USA). Protein expression was quantified by analyzing a representative autoradiograph with Image Image J software (public domain software developed at the Research Services Branch, National Institute of Mental Health, Bethesda, MD, USA) [56].

\section{Results}

\section{Patient-derived orthotopic xenograft models of TNBC}

We developed a panel of seven TNBC xenograft tumors from six patients, generated from six primary tumors (SUTI097, SUTI103, SUTI110, SUTI151, SUTI319, SUTI368) and one soft tissue metastasis in the quadriceps muscle of the leg (SUTI151M). In general, these xenografts represented aggressive TNBC. Most patients from whom the xenografts were derived had poor disease-free survival despite treatment with multiple standard therapies, with four of five patients who had follow-up greater than one year showing metastatic recurrence or death from disease (Table S3 in Additional file 3).

We compared the xenograft tumors to the corresponding patient tumors by histology, clinical biomarker expression, genome-wide array $\mathrm{CGH}$, and PIK3CA sequencing. Based on hematoxylin and eosin $(\mathrm{H} \& \mathrm{E})$ staining (Figure $1 \mathrm{~A}, \mathrm{~B})$, the original TNBC tumors exhibited a variety of histologies that were conserved in the corresponding xenografts. Specifically, there were similarities in cancer cell morphology, mitotic index, stromal abundance and percent necrosis. As expected, all xenografts were confirmed to be triple-negative by ER, PR and HER2 staining using the same clinical laboratory protocols as were performed on the patient samples (Figure 1C-E).

To compare global genomic profiles between patient tumors and their corresponding xenografts, we performed array comparative genomic hybridization (aCGH) on two tumors, SUTI110 and SUTI151. The xenograft tumors faithfully maintained the genomic DNA alterations observed in the corresponding patient tumors (Figure 2 and Figure S1 in Additional file 4). Interestingly, a previously unreported 5q11-12 deletion was observed in both patient tumor SUTI151 and its corresponding xenograft (Figure 2), and was also maintained in the xenograft of the soft tissue metastasis, SUTI151M, that developed months later (data not shown).

PIK3CA sequencing showed that two of the seven (29\%) patient primary and metastatic tumors and xenografts contained missense mutations (Figure 3A, B). SUTI097 patient and xenograft samples contained an exon 6 mutation (1173 A $>$ G, I391M); SUTI110 patient and xenograft samples contained an exon 20 


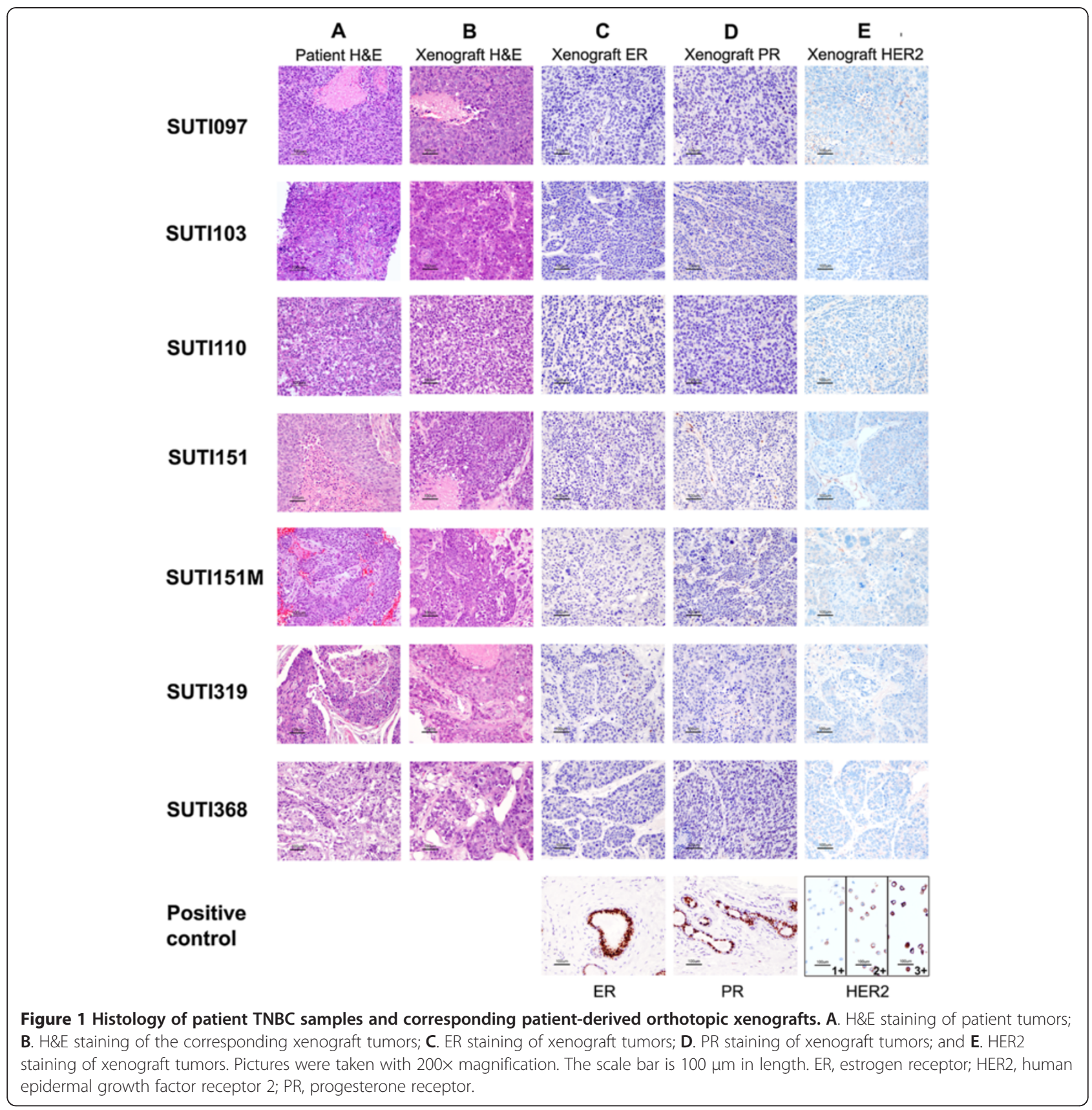

mutation (3302 G > C, G1049R). We did not observe any exon 9 mutations, which are common mutation sites in ER positive tumors.

We also detected multiple SNPs in introns flanking the sequenced PIK3CA exons, and these sequence variations were also maintained between all primary tumors and their corresponding xenografts (SUTI097, SUTI103, SUTI319, SUTI368, Figure 3C). In the one soft tissue metastasis, however, the metastatic tumor showed an additional SNP not present in the primary tumor or in the xenografts generated from the patient's primary or metastatic tumors (SUTI151 and SUTI151M). When sequence variations were analyzed between multiple xenograft tumor passages for primary tumor SUTI319, passage 3 of its xenograft tumor and passage 5 of its xenograft tumor, both before and after rapamycin treatment, there was conservation of three SNPs identified in introns between exons 5 and 6 , and between exons 6 and 7 (Figure 3C). In summary, our xenografts recapitulated the histology, biomarker status, genomic profile and PIK3CA sequence of corresponding primary patient tumors. 


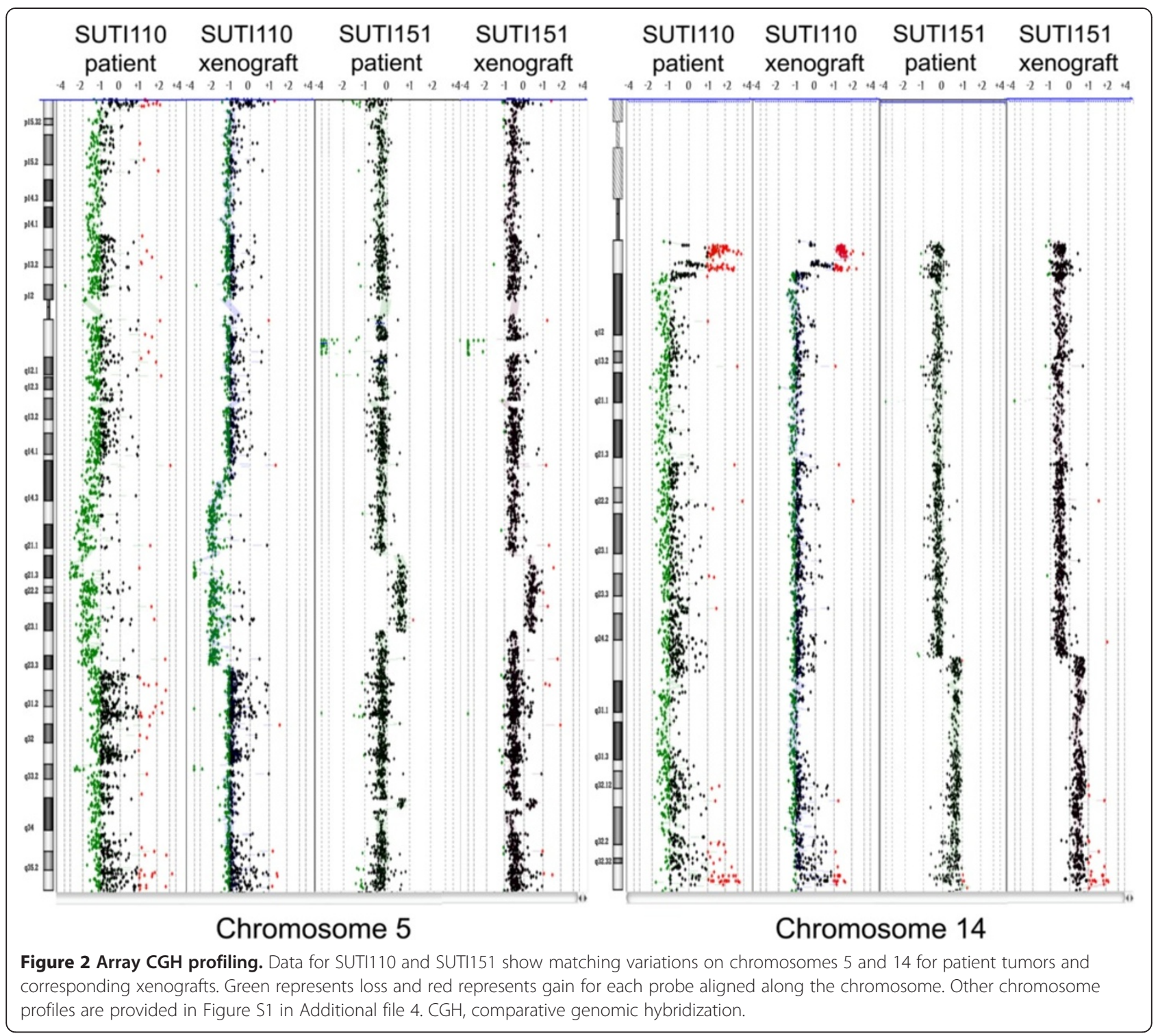

The xenograft models represent multiple TNBC subtypes Human TNBCs have been shown to be heterogeneous, comprised of at least six stable subtypes and a possible seventh unstable subtype [7]. To determine the subtypes of our panel of TNBC xenografts, we performed microarray analyses on the xenograft tumors and classified them according to the method developed by Pietenpol's group $[7,8]$. As shown in Table 1 , of our panel of seven TNBC xenograft tumors, five xenografts subclassified into four of the six stable subtypes; two were classified with Pietenpol's "unstable" group. In particular, SUTI097 belonged to the immunomodulatory (IM) subtype; SUTI103 and SUTI110 were classified as basal-like 1 (BL1); SUTI151 was classified as basal-like 2 (BL2); SUTI151M, the soft tissue metastasis of SUTI151, was identified as mesenchymal (M) subtype; and SUTI319 and SUTI368 clustered with the "unstable" group of TNBCs. We find it anecdotally fitting that the metastasis of a BL2 subtype subclassified as M subtype, which is associated with increased expression of genes involved in cell motility, cellular differentiation, growth pathways and TGF- $\beta$ signaling [7]. Our xenograft panel thus represents a majority of TNBC subtypes, making it suitable for preclinical drug testing.

\section{Rapamycin response signature and its validation}

To explore how commonly rapamycin sensitivity is expected to occur among diverse breast cancers, including TNBC, we developed a rapamycin response signature that would predict sensitivity or resistance based on a cancer's gene expression. This builds on our previous work with gene expression-based signatures, which were derived using the same approach, and which showed 


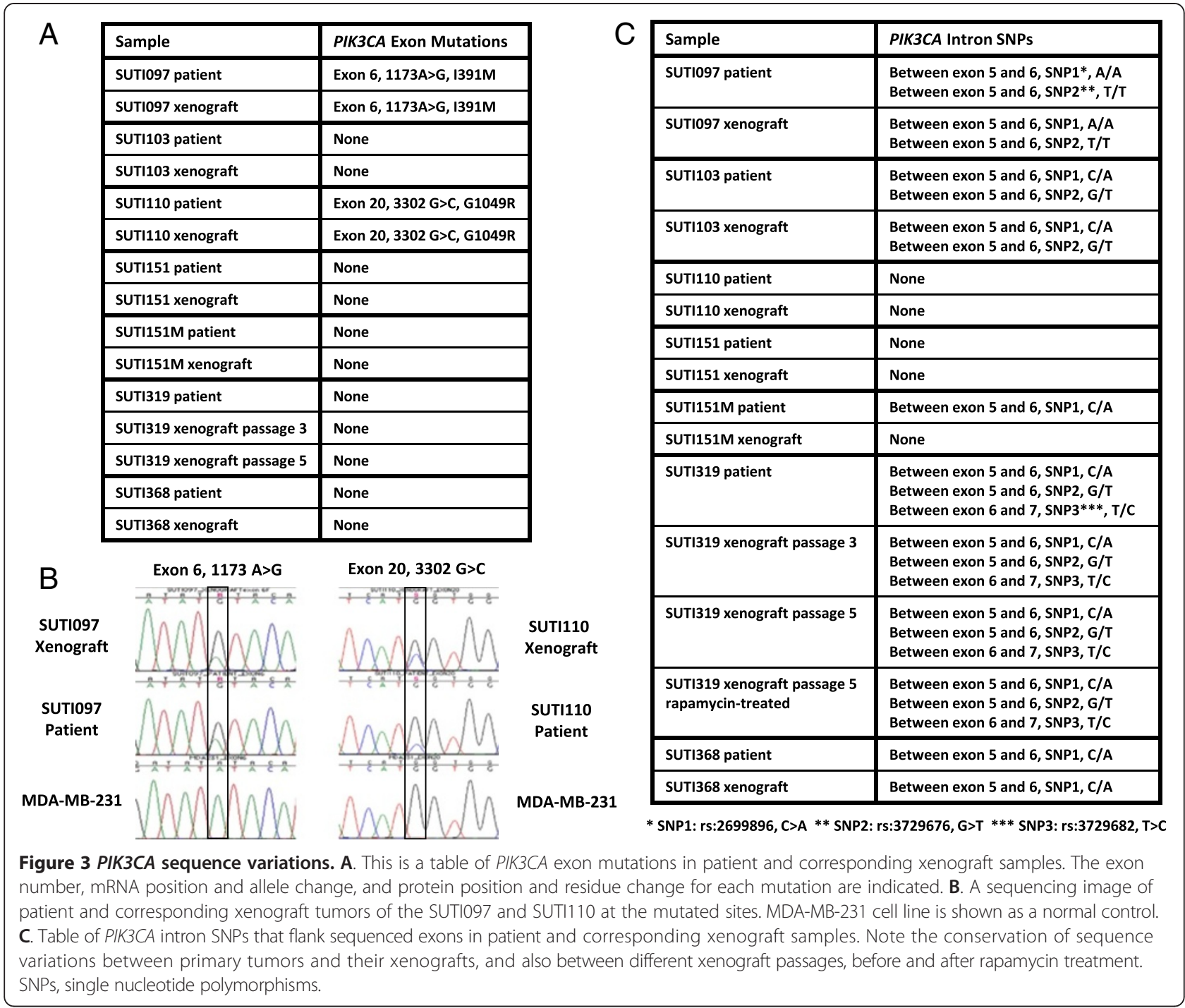

that drug response signatures predict whether a tumor or cell line will be sensitive or resistant to a drug $[49,51,52]$. The rapamycin response signature contained 200 probe sets and represented 175 unique genes (See Table S4 in Additional file 5). Figure 4A shows the

Table 1 Classification of xenograft tumors based on TNBC subtypes

\begin{tabular}{ll}
\hline Xenograft ID & TNBC subtype \\
\hline SUTI097 & immunomodulatory (IM) \\
SUTI103 & basal-like 1 (BL1) \\
SUTI110 & basal-like 1 (BL1) \\
SUTI151 & basal-like 2 (BL2) \\
SUTI151M & mesenchymal (M) \\
SUTI319 & unstable (UNS) \\
SUTI368 & unstable (UNS) \\
\hline
\end{tabular}

TNBC, Triple-negative breast cancer. heatmap view of the expression pattern of the probe sets from the signature in the training set samples from the Connectivity Map database [50] displaying expression changes in response to rapamycin treatment. When analyzed by leave-one-out cross validation, a method that leaves a single sample out to predict whether it will be classified as treated (probability $>0.5$ on the $y$-axis) or untreated (probability $<0.5$ on the y-axis), 22 of 23 training set samples showed the expected prediction, including all five treated cell line samples (Figure 4B), indicating high consistency and robustness of our signature.

To validate our rapamycin response signature in TNBC, we next tested its accuracy on an independent external dataset containing both in vitro and in vivo rapamycin treatment samples that were generated from the TNBC cell line MDA-MB-468 [26]. For both the in vitro MDAMB-468 cells and the 22-day xenografts, the treated samples were all correctly predicted to be more like the 

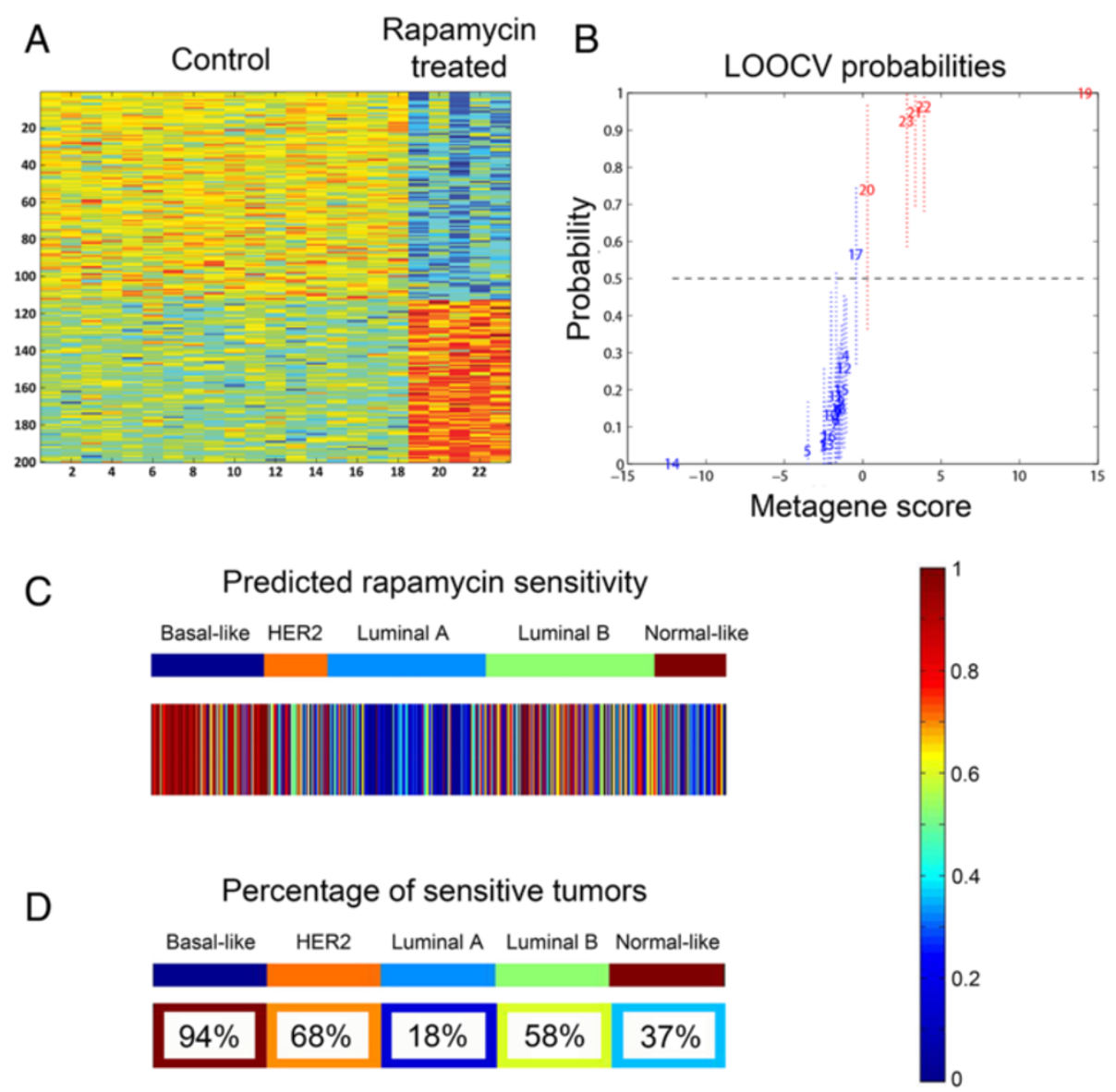

Figure 4 Rapamycin response signature. A. Heatmap of rapamycin response signature gene expression of training set samples with 18 control samples on the left and 5 rapamycin treated samples on the right. Each row is a probe set in the signature. Red indicates up-regulation and blue indicates down-regulation of the gene. B. LOOCV from the Connectivity Map training set samples. On the $y$-axis, $0=$ predicted as untreated; $1=$ predicted as treated. Control samples are in blue, and rapamycin treated samples in red. Note that only one control sample was misclassified. C. Heatmap of predicted rapamycin response of 1,401 human breast tumors with a color scaled from red to blue indicating a high to low predicted sensitivity. Each column represents an individual tumor sample, grouped by intrinsic subtypes. D. The percent of samples with predicted rapamycin sensitivity of $>0.5$ for each intrinsic subtype. The background color represents the overall sensitivity of each subtype at the same scale used in 1C. LOOCV, leave-one-out cross-validation.

treated samples in the signature training set, and hence more resistant to further rapamycin treatment, than the untreated MDA-MB-468 cells $(P=0.0017)$ and xenografts $(P=0.06)$ (Figure S2A in Additional file 6). These data confirm that the rapamycin response signature can distinguish TNBC cells that have been treated with rapamycin from untreated TNBC cells.

We also tested the rapamycin response signature on other samples in the Connectivity Map that had available treatment data on rapamycin as well as other drugs. As shown in Figure S2B in Additional file 6, only samples treated with rapamycin or PI3K inhibitors showed the expected rapamycin response signature posttreatment pattern whereas the samples treated with random drugs did not $(P<0.0001)$.

Finally, to show that the response signature does predict sensitivity and resistance to rapamycin, we compared predictions of the rapamycin response signature in a panel of
18 breast cancer cell lines to the actual EC50 obtained when these cells were treated with rapamycin. As shown in Figure S3 in Additional file 6, we found a significant correlation between signature prediction and in vitro drug sensitivity as measured by EC50 $(r=-0.3 ; P=0.02)$. Therefore, the response signature was confirmed to also be a predictor of sensitivity to rapamycin.

\section{Rapamycin sensitivity in intrinsic breast cancer subtypes}

We then used the rapamycin response signature to perform a supervised analysis of eight published gene expression datasets including 1,401 breast cancer samples from patients that were classified into the five intrinsic molecular subtypes [54]. As shown in Figure 4C, D, 94\% of BLBCs, $68 \%$ of HER2-overexpressing tumors, $18 \%$ of luminal A tumors, $58 \%$ of luminal B tumors and $37 \%$ of normal-like tumors were predicted to be sensitive to rapamycin. The predicted rapamycin sensitivity differed 
between subtypes, with the more aggressive subtypes - such as basal-like, HER2-overexpressing and luminal B - having much more frequently predicted sensitivities. Among them, BLBC had the highest frequency of rapamycin-sensitive tumors. Signatures for other PI3K pathway inhibitors showed similar patterns of predicted drug response among the different subtypes (data not shown).

\section{Rapamycin and CCl-779 significantly inhibit tumor growth in our TNBC xenograft models}

We next used our panel of seven TNBC xenografts to evaluate rapamycin sensitivity in vivo, measuring growth inhibition of two mTOR inhibitors, rapamycin (sirolimus) and/or its analog, CCI-779 (temsirolimus) and doxorubicin, a drug widely used to treat TNBC. Compared to untreated tumors, growth rates of doxorubicintreated tumors in all seven orthotopic xenograft models showed only a minimum to partial response, with growth inhibition ranging from 2 to $52 \%$ (Figure 5 and Table S3 in Additional file 3). In sharp contrast, the overall efficacy of rapamycin and CCI-779 was significantly higher than doxorubicin for the treatment of these TNBC xenografts $(P=0.0003$, Figure 5$)$. On average, rapamycin inhibited tumor growth by $94 \%$ (range 77 to $99 \%$ ), whereas the average inhibition by doxorubicin was only 36\% (Figure 5, and Table S3 in Additional file 3). This supports the hypothesis that TNBCs are highly sensitive to rapamycin. For the four xenografts treated with both mTOR inhibitors, drug efficacy was similar. However, none of the tumors disappeared completely, with most maintaining a small volume of residual tumor, suggesting that additional drugs may be necessary in combination with mTOR inhibitors to totally ablate residual disease.

\section{mTOR pathway activation in patient-derived TNBC xenografts}

To identify pathway activation, we performed Western blot analyses on PTEN and other mTOR pathway proteins. As shown in Figure 6, the protein levels of PTEN vary among the xenografts. SUTI097, SUTI110, SUTI319 and SUTI368 have relatively higher PTEN protein levels than xenografts SUTI103, SUTI151, SUTI151M, although all samples exhibited in vivo sensitivity to mTOR inhibitors (Figure 5). The PTEN levels generally remained consistent pre- and post-treatment and its expression did not appear to be associated with any particular TNBC subtype.

Phosphorylated mTOR and its downstream proteins 4EBP1, S6K1 and eIF4E - were detected in all xenograft samples (Figure 6), demonstrating baseline mTOR pathway activation. Treatment with one or both mTOR inhibitors decreased phosphorylation of mTOR and, to varying extents, its downstream proteins. The exception was metastatic tumor xenograft SUTI151M (Figure 6), although both treatments still inhibited its growth by over $90 \%$, raising the possibility of other potential modes of action of mTOR inhibitors. For all primary tumor xenografts, the overall phosphorylation of mTOR, S6K1, 4EBP1 and eIF4E proteins was decreased by 53\%, 33\%, $62 \%$ and $64 \%$, respectively, in rapamycin-treated tumors compared with tumors in the pretreatment and control groups (Table S5 in Additional file 7), supporting decreased mTOR pathway activity after treatment.

\section{Discussion}

Developing more effective therapies would be of significant benefit to patients with TNBC. We describe here multiple patient-derived orthotopic xenograft models that molecularly mimic patients' original tumors and represent diverse TNBC subtypes. We use these to demonstrate the promising potency of mTOR inhibitors as suggested by in silico testing of a rapamycin response signature generated by our group.

We demonstrated that our models closely recapitulated original patient tumors morphologically, by molecular biomarkers, global copy number variation and PIK3CA sequencing. Such patient-derived models have also been demonstrated by others to faithfully maintain histology [57-63], gene expression patterns [60-63] and genomic features $[57,58,61,63,64]$ in diverse human breast cancers, including triple-negative, ER positive and HER2-overexpressing tumors. These models have also been shown to be effective for preclinical therapeutic studies $[45,46,57,58,62,63,65,66]$.

By sequencing, we observed PIK3CA mutations in two of our seven (29\%) patient and xenograft pairs of TNBC tumors, with mutations in exon $6(\mathrm{I} 391 \mathrm{M}, \mathrm{n}=1)$, and exon 20 (G1049R, n=1). We also noted complete conservation of multiple SNPs in the flanking introns adjacent to the sequenced exons for the primary tumors, even on subsequent xenograft passages. The soft tissue metastasis of one of the primary tumors contained an intron SNP, which was not observed in the primary tumor or in the xenografts of the primary or metastatic tumor. The reason for this is unclear but may reflect lack of depth of our sequencing or increased heterogeneity in metastases.

Whole exome sequencing of 93 basal-like breast cancers by the Cancer Genome Atlas Network [34] identified PIK3CA mutations in 9 (10\%). These were present in exon $1(\mathrm{R} 88 \mathrm{Q}, \mathrm{n}=1$; $\mathrm{R} 108 \mathrm{H}, \mathrm{n}=1)$, exon $4(\mathrm{~N} 345 \mathrm{~K}$, $\mathrm{n}=1$ ), exon 9 (E542K, $\mathrm{n}=1$ ), exon 12 (F614I, $\mathrm{n}=1$ ) and, most commonly, exon $20(\mathrm{H} 1047 \mathrm{R}, \mathrm{n}=4)$, none of which were detected in our panel. Another sequencing series has reported a $10 \%$ PIK3CA mutation rate in 65 TNBCs [35], with one mutation in exon 9 (E545K) and most in exon 20 (H1047R). For technical reasons, whole exome sequencing may not always identify mutations 

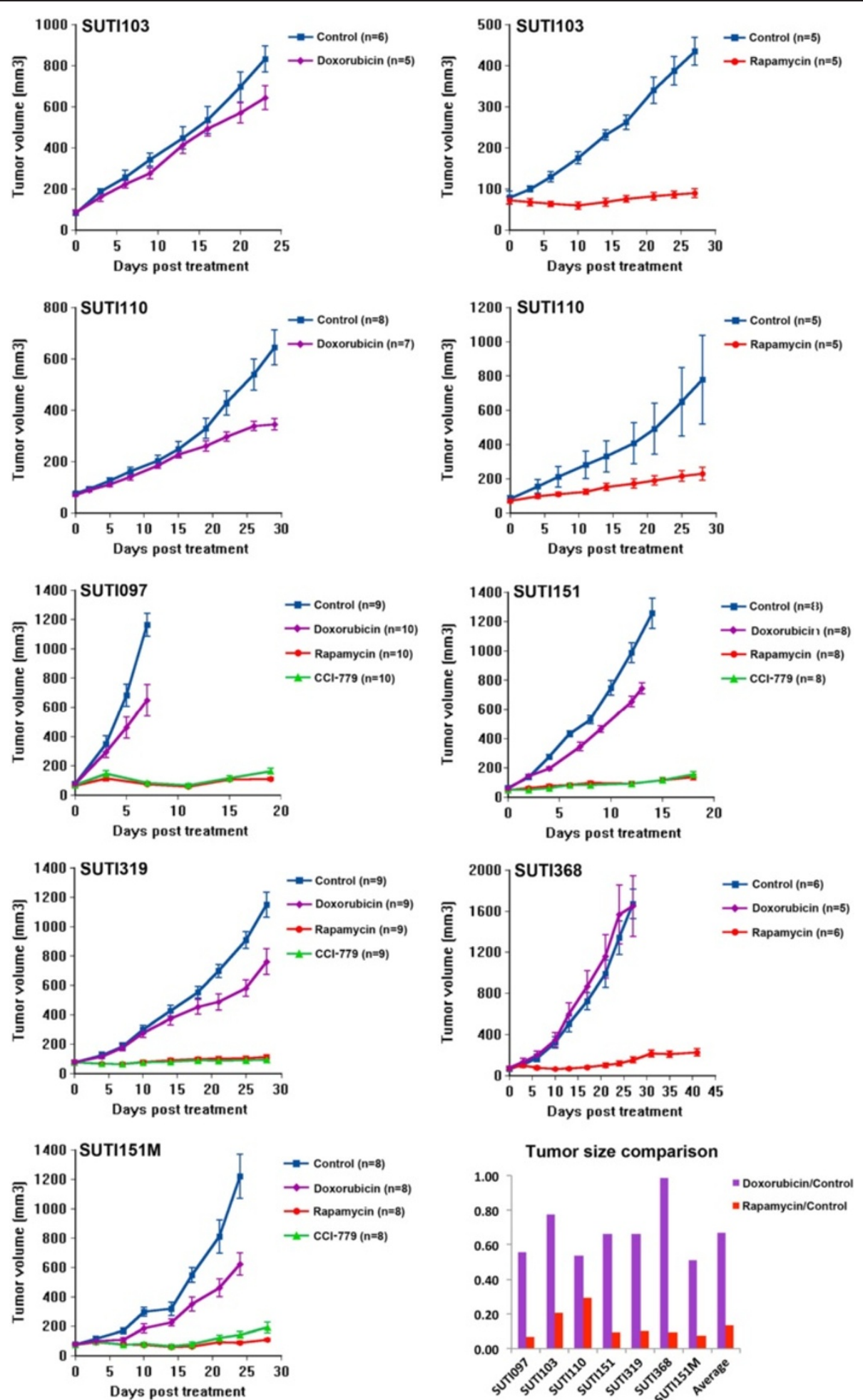

Figure 5 In vivo growth curves of seven patient-derived orthotopic xenografts of TNBC. Treatment with vehicle control in blue; doxorubicin in purple; rapamycin in red; CCl-779 in green. Tumor volumes in $\mathrm{mm}^{3}$. Each data point represents the mean tumor volume of each treatment group. Error bars represent standard error of the mean. CCI-779, temsirolimus; TNBC, triple-negative breast cancer. 


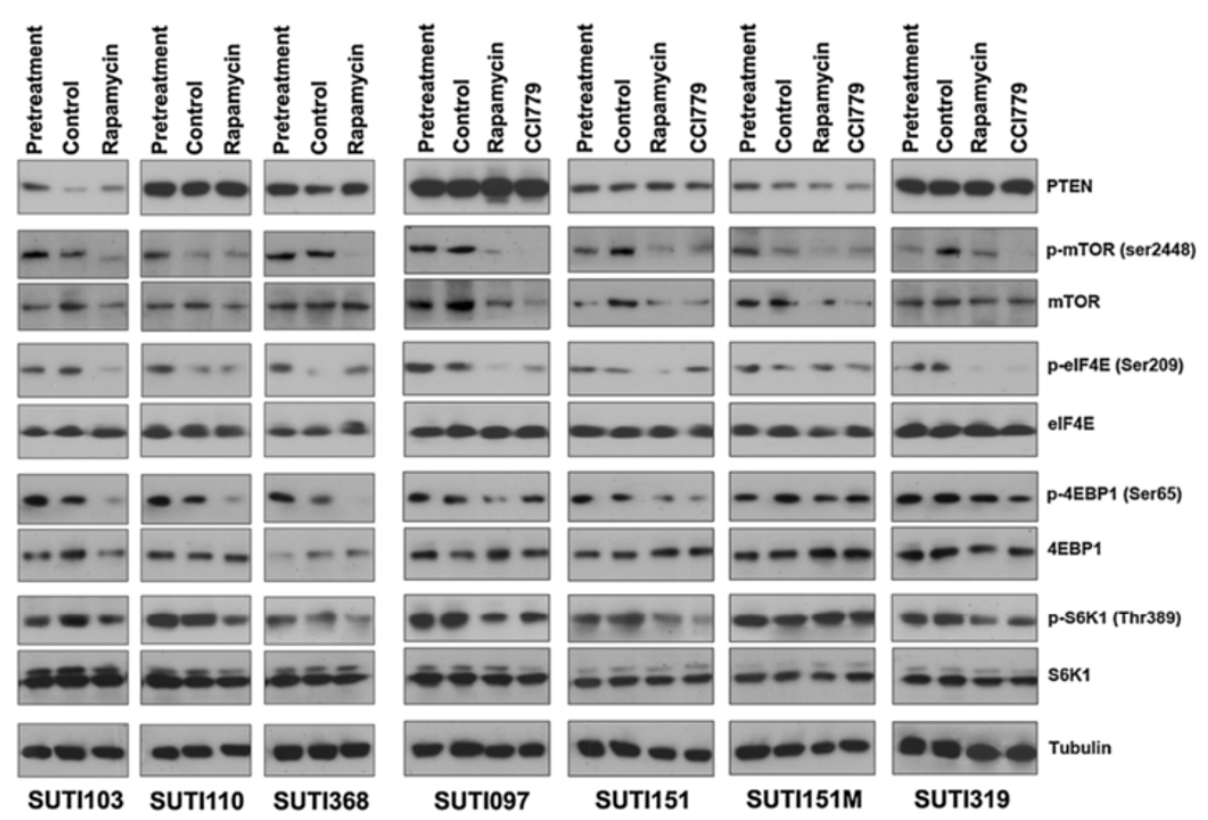

Figure 6 Protein expression and phosphorylation of PTEN, mTOR, S6K1, 4EBP1, and elF4E in xenografts. Western blot images were cropped at the molecular weight of each of the target proteins. Pretreatment samples were collected prior to initiation of treatment; control samples (vehicle control), rapamycin-treated and CCI-779-treated samples were collected at the end of the treatment period. Tubulin was used as a loading control. See also Table S5 in Additional file 7. CCl-779, temsirolimus.

when the mutant cells make up less than $10 \%$ of the sample or because of lack of adequate sequencing coverage or depth. Thus, when a mass spectroscopy approach evaluated SNPs for 23 known site-specific mutations in PIK3CA, $8 \%$ of 240 TNBCs revealed mutations located in exon $4(\mathrm{~N} 345 \mathrm{~K})$, exon 7 (E418K), exon 9 (E545K, E542K, P539R) and exon 20 (H1047R, H1047L, H1047Y, G1049R) [67]. In sum and including our tumors, PIK3CA mutations in TNBC have now been identified in exons 1 , $4,6,7,9,12$ and 20 . We also note that despite the known genomic instability of TNBCs [68], we observed that all PIK3CA sequence variations persisted between patient primary tumors and xenograft models, and between xenograft models assayed during different sequential passages.

Our seven patient-derived xenograft models spanned different TNBC subtypes as described by Pietenpol's group $[7,8]$, who analyzed gene expression profiles of 587 TNBCs from 21 datasets to determine different TNBC subtypes. They identified six stable subtypes and an unstable subtype (UNS). The stable subtypes included two basal-like (BL1 and BL2), an immunomodulatory (IM), a mesenchymal (M), a mesenchymal stem-like (MSL), and a luminal androgen receptor (LAR). Using their analytic tools, we found that five of our seven TNBC xenografts represented four stable subtypes (BL1, BL2, $M$ and IM), and two were in the UNS group, confirming our panel's subtype diversity. Chang's group recently analyzed 15 patient-derived TNBC xenografts and found that 12 spanned three subtypes (BL1, $n=8 ; M, n=3$;
BL2/IM, $\mathrm{n}=1$ ) with three xenografts unclassified [69]. MSL and LAR subtypes were not identified in our or Chang's series of patient-derived xenograft models.

Interestingly, we found that a xenograft generated from a primary tumor (SUTI151) was classified as basallike 2 (BL2), whereas the xenograft generated from its soft tissue metastasis (SUTI151M) was classified as mesenchymal (M). The BL2 subtype expresses genes involved in growth factor signaling, glycolysis and gluconeogenesis, whereas the $M$ subtype is enriched for genes involved in cell motility, extracellular matrix receptor interaction and cell differentiation pathways, including the Wnt pathway, anaplastic lymphoma kinase (ALK) pathway and TGF- $\beta$ signaling [7]. This adds support to the idea that distant metastases acquire different signaling programs than the primary tumor.

Here, we developed and validated a rapamycin response signature that predicts sensitivity and resistance to rapamycin. The signature predicted that the majority of BLBCs should be sensitive to rapamycin, suggesting activation of the mTOR pathway in this subtype. This is consistent with data from the Cancer Genome Atlas Network group [34]. They analyzed PI3K pathway activation in 390 human breast tumors across five intrinsic subtypes using mRNA expression signatures from different sources. Signatures from both Saal et al. (PTEN loss in human breast tumors) and Connectivity Map (PI3K/mTOR inhibitor treatment in vitro) showed similar patterns: the basal-like subtype had the highest PI3K pathway activity 
and luminal A had the lowest pathway activity [32,34]. These results agree with our rapamycin response signature predictions. In addition, they show that BLBCs have the highest expression levels of PI3K/AKT pathway genes, as well as a high PIK3CA gene amplification rate (49\%) [34]. Also consistent is that protein levels of the mTOR pathway suppressors, PTEN and INPP4B, are relatively low in BLBC or TNBC patient tumors compared with other breast cancer subtypes [14,32,34,36]; and mTOR pathway-related proteins, especially AKT and 4EBP1, show high phosphorylation levels in BLBCs [33,34]. Moreover, Moestue et al. recently demonstrated that BEZ235, a dual PI3K/mTOR inhibitor, had potent in vivo efficacy in a patient-derived BLBC xenograft model, but not in a luminal model [70], also supporting our findings.

Clinically, breast cancers are more commonly classified by their biomarkers (ER, PR and HER2) rather than by microarray analysis. As described above, most TNBCs (about 70 to $80 \%$ ) are basal-like subtypes by gene expression analysis. It is thus reasonable to expect high rapamycin sensitivity among TNBCs according to our prediction model. This was confirmed by a remarkable 77 to $99 \%$ growth inhibition of either drug (mean 94\%), whereas the average inhibition by doxorubicin was only $36 \%$.

Supporting our growth inhibition findings, we showed that the mTOR pathway was activated in all our TNBC patient-derived xenografts, as indicated by the phosphorylation of mTOR and downstream proteins 4EBP1 and S6K1. This is consistent with observations in human TNBCs $[33,34]$. After treatment of the xenografts generated from primary tumors, overall decreased phosphorylation of these proteins suggested decreased mTOR pathway activity, which may have contributed to observed tumor growth inhibition. We observed that mTOR inhibitor treatment exerted a greater decrease in 4EBP1 phosphorylation (62\%) than in S6K1 phosphorylation (33\%), although individual tumor responses varied.

In our study, mTOR inhibitors showed a cytostatic effect on tumor growth (growth inhibition) but did not reduce original tumor volume over time. To obtain tumor shrinkage or complete ablation, it is likely that additional drugs need to be added. Supporting this is a negative Phase II single drug study of another mTOR inhibitor, everolimus, which did not show partial or complete responses in any of five ER negative/HER2 negative patients with metastatic breast cancer [71]. In contrast, a recent phase II clinical trial evaluating temsirolimus and carboplatin achieved a $36 \%$ clinical benefit rate of patients with metastatic triple-negative breast cancer [42]. As well as investigating the addition of mTOR inhibitors to current therapies, new drug combinations are also under study, such as mTOR catalytic inhibitors, dual kinase inhibitors of mTOR and PI3K, and combined targeting of the selective allosteric pan-AKT inhibitor
MK-2206 with mTOR inhibition [70,72-76]. We are optimistic that mTOR inhibitors will broadly affect the treatment of breast cancer, especially TNBCs.

\section{Conclusions}

In summary, we generated seven patient-derived orthotopic xenograft models of TNBC that matched original patient primary and metastatic tumors by histology, biomarkers, genomic features and PIK3CA sequencing. These models spanned at least four of six TNBC subtypes. We developed a rapamycin response signature that predicted sensitivity in BLBCs. Testing two mTOR inhibitors in our TNBC xenograft models, we confirmed in vivo growth inhibition in all. Our data suggest that mTOR pathway inhibition warrants further preclinical and clinical investigation in TNBC in conjunction with other drugs.

\section{Additional files}

Additional file 1: Table S1. Primer sets for PIK3CA mutational analyses. Additional file 2: Table S2. GEO breast cancer microarray datasets used in Figure 4

Additional file 3: Table S3. Summary of therapeutic responses in patient-derived xenograft models of TNBC and clinical responses to standard chemotherapy.

Additional file 4: Figure S1. Array CGH profiles of all chromosomes comparing patient $(\mathrm{p})$ and xenograft $(\mathrm{x}$ ) for samples SUTI 151 and SUTI 110

Additional file 5: Table S4. Rapamycin response signature probes. Table showing 200 Affymetrix probes making up the rapamycin response signature. The probes are annotated with gene name, gene symbol and weight given to each probe relative to the first principal component in the rapamycin-response signature.

Additional file 6: Figure S2. Validations of rapamycin response prediction. A. Plots of predicted rapamycin sensitivity of MDA-MB-468 cells based on GEO data set GSE18571. As indicated, MDA-MB-468 was treated with either vehicle control (DMSO) or rapamycin in both cell culture and xenografts. Xenograft tumors were collected after 1 day or 22 days of treatment. B. Plots of predicted sensitivity to rapamycin in Connectivity Map samples from nine independent batches. Samples are grouped as untreated controls (Untreated), rapamycin-treated (Rapamycin), PI3K inhibitors-treated (PI3K inhibitors), or treated with drugs other than rapamycin or PI3K inhibitors (Other drugs). The bar showed the mean of the predicted sensitivity with 1 as the highest and 0 the lowest predicted sensitivity to rapamycin. Figure S3 Correlation of actual sensitivity and predicted sensitivity. Correlation of actual sensitivity to rapamycin treatment (indicated by EC50) and predicted sensitivity by the rapamycin response signature of 18 breast cancer cell lines (scattered dots). A regression line was drawn to show the degree of correlation.

Additional file 7: Table S5. Phosphorylation levels of S6K1, 4EBP1, elF4E and mTOR by immunoblot after rapamycin or CCl-779 treatment.

\section{Abbreviations}

4EBP1: eukaryotic translation initiation factor $4 \mathrm{E}$ binding protein 1; aCGH: array comparative genomic hybridization; AKT: protein kinase B; BL 1: basal-like 1; BL2: basal-like 2; BLBC: basal-like breast cancer; CCI-779: temsirolimus; DMSO: dimethyl sulfoxide; EGFR: epidermal growth factor receptor; ER: estrogen receptor; FBS: fetal bovine serum; H\&E: hematoxylin and eosin; HER2: human epidermal growth factor receptor 2; IM: immunomodulatory; INPP4B: inositol polyphosphate-4-phosphatase, type II; IP: intraperitoneal; LAR: luminal androgen receptor; LKB1: serine-threonine kinase 1; LOOCV: leave-one-out cross-validation; M: mesenchymal; MSL: mesenchymal stem-like; mTOR: mammalian target of 
rapamycin; PBS: phosphate-buffered saline; PI3K: phosphatidylinositide 3-kinase; PIK3CA: phosphatidylinositol-4,5-bisphosphate 3-kinase, catalytic subunit alpha; PR: progesterone receptor; PTEN: phosphatase and tensin homologue; S6K1: p70 ribosomal S6 kinase 1; SNP: single nucleotide polymorphism; TGF- $\beta$ : transforming growth factor-beta; TNBC: triple-negative breast cancer; TSC: tuberous sclerosis complex; UNS: unstable.

\section{Competing interests}

The authors declare that they have no competing interests.

\section{Authors' contributions}

$H Z$, SSJ, AHB, ALC and GVG conceived the study and MLT and SHD helped with its design. ILW, FMD and SSJ provided patient tumor tissue and clinical data, and ILW, GVG and SSJ performed clinical data analyses. HZ generated tumor xenografts and prepared samples for microarray analysis. TAL analyzed all pathology data. GD and $\mathrm{MH}$ performed and analyzed the array $\mathrm{CGH}$ studies, with additional interpretation and compilation by DOF. HZ and SK performed and analyzed DNA sequencing. MAC performed tumor subtyping using microarray data. ALC and AHB developed and validated the drug response signature, applied the signature to breast tumor datasets, and analyzed results. $\mathrm{HZ}$ and $\mathrm{CMP}$ performed in vivo drug testing and data acquisition. HZ, SSJ and GVG interpreted drug response in xenografts. SV and $\mathrm{BL}$ performed and analyzed Western blots, with additional interpretation by ACM. HZ, SSJ, ALC, AHB, GVG, SK, ILW, SV, GD, MAC, TAL, DOF and BL wrote the manuscript, while CMP, MH, MLT, FMD, ACM and SHD provided further input to the manuscript and/or critical revisions. All authors read, commented on and approved the final manuscript.

\section{Acknowledgements}

The authors thank Pauline Chu for immunohistology assistance, Farbod Babrzadeh for assistance with the PIK3CA mutation analyses, and Kyra Heirich for help with manuscript review. This study was supported in part by National Institutes of Health grant R01GM085601 (SSJ and AHB), the California Breast Cancer Research Program of the University of California, Grant Number 11IB-0175 (SSJ), the John and Marva Warnock Cancer Research Fund, the Andrew and Debra Rachleff family fund, the Solomon R. and Rebecca D. Baker Foundation, and Cancer Research UK core funding of the London Research Institute (BL and RV).

\section{Author details}

'Division of Surgical Oncology, Stanford University School of Medicine, Stanford, CA 94305, USA. ${ }^{2}$ Division of Oncology, Huntsman Cancer Institute, University of Utah, Salt Lake City UT 84112, USA. ${ }^{3}$ Stanford Genome Technology Center, Stanford University School of Medicine, Palo Alto, CA 94304, USA. ${ }^{4}$ Cell Biophysics Laboratory, London Research Institute, Cancer Research UK, London, UK. ${ }^{5}$ College of Life Science and Chemistry, Wuhan Donghu University, Wuhan, Hubei, China. ${ }^{6}$ Department of Health Research and Policy (Biostatistics), Stanford University School of Medicine, Stanford, CA 94305, USA. 'Department of Medical Sciences, School of Veterinary Medicine, University of Wisconsin-Madison, Madison, WI 53706, USA. ${ }^{8}$ Department of Pathology, Stanford University School of Medicine, Stanford, CA 94305, USA. ${ }^{9}$ Life Technologies Corporation, Department of Medical Sciences, Foster City, CA 94404, USA. ${ }^{10}$ Department of Microbiology and Immunology, Stanford University School of Medicine, Stanford, CA 94305, USA. ${ }^{11}$ Division of Medical Oncology, Stanford University School of Medicine, Stanford, CA 94305, USA. ${ }^{12}$ California Pacific Medical Center Research Institute, San Francisco, CA 94107, USA. ${ }^{13}$ Sanford-Burnham Medical Research Institute, La Jolla, CA 92037, USA. ${ }^{14}$ Department of Pharmacology and Toxicology, University of Utah, Salt Lake City, UT 84112, USA.

Received: 22 June 2013 Accepted: 25 March 2014

Published: 7 April 2014

\section{References}

1. Dent R, Trudeau M, Pritchard Kl, Hanna WM, Kahn HK, Sawka CA, Lickley LA, Rawlinson E, Sun P, Narod SA: Triple-negative breast cancer: clinical features and patterns of recurrence. Clin Cancer Res 2007, 13:4429-4434.

2. Badve S, Dabbs DJ, Schnitt SJ, Baehner FL, Decker T, Eusebi V, Fox SB, Ichihara S, Jacquemier J, Lakhani SR, Palacios J, Rakha EA, Richardson AL, Schmitt FC, Tan PH, Tse GM, Weigelt B, Ellis IO, Reis-Filho JS: Basal-like and triple-negative breast cancers: a critical review with an emphasis on the implications for pathologists and oncologists. Mod Pathol 2011, 24:157-167.

3. Kyndi M, Sørensen FB, Knudsen H, Overgaard M, Nielsen HM, Overgaard J, Danish Breast Cancer Cooperative Group: Estrogen receptor, progesterone receptor, HER-2, and response to postmastectomy radiotherapy in high-risk breast cancer: the Danish Breast Cancer Cooperative Group. J Clin Oncol 2008, 26:1419-1426.

4. Perou CM, Sørlie T, Eisen MB, van de Rijn M, Jeffrey SS, Rees CA, Pollack JR, Ross DT, Johnsen H, Akslen LA, Fluge O, Pergamenschikov A, Williams C, Zhu SX, Lønning PE, Børresen-Dale AL, Brown PO, Botstein D: Molecular portraits of human breast tumours. Nature 2000, 406:747-752.

5. Prat A, Adamo B, Cheang MC, Anders CK, Carey LA, Perou CM: Molecular characterization of basal-like and non-basal-like triple-negative breast cancer. Oncologist 2013, 18:123-133.

6. Bertucci F, Finetti P, Cervera N, Esterni B, Hermitte F, Viens P, Birnbaum D: How basal are triple-negative breast cancers? Int J Cancer 2008, 123:236-240.

7. Lehmann BD, Bauer JA, Chen X, Sanders ME, Chakravarthy AB, Shyr Y, Pietenpol JA: Identification of human triple-negative breast cancer subtypes and preclinical models for selection of targeted therapies. J Clin Invest 2011, 121:2750-2767.

8. Chen X, Li J, Gray WH, Lehmann BD, Bauer JA, Shyr Y, Pietenpol JA: TNBCtype: a subtyping tool for triple-negative breast cancer. Cancer Inform 2012, 11:147-156.

9. Manning BD, Cantley LC: AKT/PKB signaling: navigating downstream. Cell 2007, 129:1261-1274.

10. Rubio-Viqueira B, Hidalgo M: Targeting mTOR for cancer treatment. Adv Exp Med Biol 2006, 587:309-327.

11. Foster KG, Fingar DC: Mammalian target of rapamycin (mTOR): conducting the cellular signaling symphony. J Biol Chem 2010, 285:14071-14077.

12. Watanabe $R$, Wei $L$, Huang J: mTOR signaling, function, novel inhibitors, and therapeutic targets. J Nucl Med 2011, 52:497-500.

13. O'Brien C, Wallin JJ, Sampath D, GuhaThakurta D, Savage H, Punnoose EA, Guan J, Berry L, Prior WW, Amler LC, Belvin M, Friedman LS, Lackner MR: Predictive biomarkers of sensitivity to the phosphatidylinositol 3' kinase inhibitor GDC-0941 in breast cancer preclinical models. Clin Cancer Res 2010, 16:3670-3683.

14. Marty B, Maire V, Gravier E, Rigaill G, Vincent-Salomon A, Kappler M, Lebigot I, Djelti F, Tourdès A, Gestraud P, Hupé P, Barillot E, Cruzalegui F, Tucker GC, Stern MH, Thiery JP, Hickman JA, Dubois T: Frequent PTEN genomic alterations and activated phosphatidylinositol 3-kinase pathway in basal-like breast cancer cells. Breast Cancer Res 2008, 10:R101.

15. Gewinner C, Wang ZC, Richardson A, Teruya-Feldstein J, Etemadmoghadam D, Bowtell D, Barretina J, Lin WM, Rameh L, Salmena L, Pandolfi PP, Cantley LC: Evidence that inositol polyphosphate 4-phosphatase type II is a tumor suppressor that inhibits PI3K signaling. Cancer Cell 2009, 16:115-125.

16. Inoki K, Li Y, Zhu T, Wu J, Guan KL: TSC2 is phosphorylated and inhibited by Akt and suppresses mTOR signaling. Nat Cell Biol 2002, 4:648-657.

17. Guertin DA, Sabatini DM: An expanding role for mTOR in cancer. Trends Mol Med 2005, 11:353-361.

18. Chung J, Kuo CJ, Crabtree GR, Blenis J: Rapamycin-FKBP specifically blocks growth-dependent activation of and signaling by the $70 \mathrm{kd} \mathrm{S6}$ protein kinases. Cell 1992, 69:1227-1236.

19. Hara K, Yonezawa K, Kozlowski MT, Sugimoto T, Andrabi K, Weng QP, Kasuga M, Nishimoto I, Avruch J: Regulation of elF-4E BP1 phosphorylation by mTOR. J Biol Chem 1997, 272:26457-26463.

20. Ma J, Meng Y, Kwiatkowski DJ, Chen X, Peng H, Sun Q, Zha X, Wang F, Wang Y, Jing Y, Zhang S, Chen R, Wang L, Wu E, Cai G, Malinowska-Kolodziej I, Liao Q, Liu Y, Zhao Y, Sun Q, Xu K, Dai J, Han J, Wu L, Zhao RC, Shen H, Zhang $\mathrm{H}$ : Mammalian target of rapamycin regulates murine and human cell differentiation through STAT3/p63/Jagged/Notch cascade. J Clin Invest 2010, 120:103-114.

21. Miller TW, Rexer BN, Garrett JT, Arteaga CL: Mutations in the phosphatidylinositol 3-kinase pathway: role in tumor progression and therapeutic implications in breast cancer. Breast Cancer Res 2011, $13: 224$.

22. Laplante M, Sabatini DM: mTOR signaling in growth control and disease. Cell 2012, 149:274-293.

23. LoPiccolo J, Blumenthal GM, Bernstein WB, Dennis PA: Targeting the PI3K/ Akt/mTOR pathway: effective combinations and clinical considerations. Drug Resist Updat 2008, 11:32-50. 
24. Zhou X, Tan M, Stone Hawthorne V, Klos KS, Lan KH, Yang Y, Yang W, Smith TL, Shi D, Yu D: Activation of the Akt/mammalian target of rapamycin/4E-BP1 pathway by ErbB2 overexpression predicts tumor progression in breast cancers. Clin Cancer Res 2004, 10:6779-6788.

25. Bärlund M, Forozan F, Kononen J, Bubendorf L, Chen Y, Bittner ML, Torhorst J, Haas P, Bucher C, Sauter G, Kallioniemi OP, Kallioniemi A: Detecting activation of ribosomal protein $\mathrm{S} 6$ kinase by complementary DNA and tissue microarray analysis. J Nat/ Cancer Inst 2000, 92:1252-1259.

26. Akcakanat A, Zhang $L$, Tsavachidis S, Meric-Bernstam F: The rapamycin-regulated gene expression signature determines prognosis for breast cancer. Mol Cancer 2009, 8:75.

27. Creighton CJ: A gene transcription signature of the Akt/mTOR pathway in clinical breast tumors. Oncogene 2007, 26:4648-4655.

28. Motzer RJ, Escudier B, Oudard S, Hutson TE, Porta C, Bracarda S, Grünwald V, Thompson JA, Figlin RA, Hollaender N, Urbanowitz G, Berg WJ, Kay A, Lebwohl D, Ravaud A, RECORD-1 Study Group: Efficacy of everolimus in advanced renal cell carcinoma: a double-blind, randomised, placebo-controlled phase III trial. Lancet 2008, 372:449-456.

29. Pavel ME, Hainsworth JD, Baudin E, Peeters M, Hörsch D, Winkler RE, Klimovsky J, Lebwohl D, Jehl V, Wolin EM, Oberg K, Van Cutsem E, Yao JC, RADIANT-2 Study Group: Everolimus plus octreotide long-acting repeatable for the treatment of advanced neuroendocrine tumours associated with carcinoid syndrome (RADIANT-2): a randomised, placebo-controlled, phase 3 study. Lancet 2011, 378:2005-2012.

30. Krueger DA, Care MM, Holland K, Agricola K, Tudor C, Mangeshkar P, Wilson KA, Byars A, Sahmoud T, Franz DN: Everolimus for subependymal giant-cell astrocytomas in tuberous sclerosis. N Engl J Med 2010, 363:1801-1811.

31. Baselga J, Campone M, Piccart M, Burris HA 3rd, Rugo HS, Sahmoud T, Noguchi S, Gnant M, Pritchard Kl, Lebrun F, Beck JT, Ito Y, Yardley D, Deleu I, Perez A, Bachelot T, Vittori L, Xu Z, Mukhopadhyay P, Lebwohl D, Hortobagyi GN: Everolimus in postmenopausal hormone-receptor-positive advanced breast cancer. N Engl J Med 2012, 366:520-529.

32. Saal LH, Gruvberger-Saal SK, Persson C, Lövgren K, Jumppanen M, Staaf J, Jönsson G, Pires MM, Maurer M, Holm K, Koujak S, Subramaniyam S, Vallon-Christersson J, Olsson H, Su T, Memeo L, Ludwig T, Ethier SP, Krogh M, Szabolcs M, Murty W, Isola J, Hibshoosh H, Parsons R, Borg A: Recurrent gross mutations of the PTEN tumor suppressor gene in breast cancers with deficient DSB repair. Nat Genet 2008, 40:102-107.

33. Montero JC, Esparís-Ogando A, Re-Louhau MF, Seoane S, Abad M, Calero R, Ocaña A, Pandiella A: Active kinase profiling, genetic and pharmacological data define mTOR as an important common target in triple-negative breast cancer. Oncogene 2014, 33:148-156.

34. The Cancer Genome Atlas Network: Comprehensive molecular portraits of human breast tumours. Nature 2012, 490:61-70.

35. Shah SP, Roth A, Goya R, Oloumi A, Ha G, Zhao Y, Turashvili G, Ding J, Tse K, Haffari G, Bashashati A, Prentice LM, Khattra J, Burleigh A, Yap D, Bernard V, McPherson A, Shumansky K, Crisan A, Giuliany R, Heravi-Moussavi A, Rosner J, Lai D, Birol I, Varhol R, Tam A, Dhalla N, Zeng T, Ma K, Chan SK, et al: The clonal and mutational evolution spectrum of primary triple-negative breast cancers. Nature 2012, 486:395-399.

36. Fedele CG, Ooms LM, Ho M, Vieusseux J, OToole SA, Millar EK, Lopez-Knowles E, Sriratana A, Gurung R, Baglietto L, Giles GG, Bailey CG, Rasko JE, Shields BJ, Price JT, Majerus PW, Sutherland RL, Tiganis T, McLean CA, Mitchell CA: Inositol polyphosphate 4-phosphatase II regulates PI3K/Akt signaling and is lost in human basal-like breast cancers. Proc Natl Acad Sci U S A 2010, 107:22231-22236.

37. López-Knowles E, OToole SA, McNeil CM, Millar EK, Qiu MR, Crea P, Daly RJ, Musgrove EA, Sutherland RL: PI3K pathway activation in breast cancer is associated with the basal-like phenotype and cancer-specific mortality. Int J Cancer 2010, 126:1121-1131.

38. Zeng Q, Yang Z, Gao YJ, Yuan H, Cui K, Shi Y, Wang H, Huang X, Wong ST, Wang $Y$, Kesari $S$, Ji RR, Xu X: Treating triple-negative breast cancer by a combination of rapamycin and cyclophosphamide: an in vivo bioluminescence imaging study. Eur J Cancer 2010, 46:1132-1143.

39. Weigelt B, Warne PH, Downward J: PIK3CA mutation, but not PTEN loss of function, determines the sensitivity of breast cancer cells to mTOR inhibitory drugs. Oncogene 2011, 30:3222-3233.

40. Meric-Bernstam F, Akcakanat A, Chen H, Do KA, Sangai T, Adkins F, Gonzalez-Angulo AM, Rashid A, Crosby K, Dong M, Phan AT, Wolff RA, Gupta S, Mills GB, Yao J: PIK3CA/PTEN mutations and Akt activation as markers of sensitivity to allosteric mTOR inhibitors. Clin Cancer Res 2012, 18:1777-1789.
41. Janku F, Wheler JJ, Naing A, Falchook GS, Hong DS, Stepanek VM, Fu S, Piha-Paul SA, Lee JJ, Luthra R, Tsimberidou AM, Kurzrock R: PIK3CA mutation H1047R is associated with response to PI3K/AKT/mTOR signaling pathway inhibitors in early-phase clinical trials. Cancer Res 2013, 73:276-284.

42. Singh JC, Novik Y, Stein S, Volm M, Meyers M, Smith J, Omene C, Speyer J, Schneider R, Jhaveri K, Formenti S, Kyriakou V, Joseph B, Goldberg JD, Li X, Adams $S$, Tiersten A: Phase 2 trial of everolimus and carboplatin combination in patients with triple negative metastatic breast cancer. Breast Cancer Res 2014, 16:R32

43. Mayer I, Burris H, Bendell J, Means-Powell J, Arteaga C, Shyr Y, Pietenpol J: A phase lb trial of RAD001, an mTOR inhibitor, with weekly cisplatin and paclitaxel in patients with HER2-negative metastatic breast cancer. Cancer Res 2009, 69(Suppl 24):Abstract 3093.

44. Gonzalez-Angulo AM, Akcakanat A, Liu S, Green MC, Murray JL, Chen H, Palla SL, Koenig KB, Brewster AM, Valero V, Ibrahim NK, Moulder-Thompson S, Litton JK, Tarco E, Moore J, Flores P, Crawford D, Dryden MJ, Symmans WF, Sahin A, Giordano SH, Pusztai L, Do KA, Mills GB, Hortobagyi GN, Meric-Bernstam F: Open label randomized clinical trial of standard neoadjuvant chemotherapy with paclitaxel followed by FEC vs. the combination of paclitaxel and everolimus followed by FEC in women with triple receptor-negative breast cancer. Ann Oncol 2014, [Epub ahead of print].

45. Hidalgo M, Bruckheimer E, Rajeshkumar NV, Garrido-Laguna I, De Oliveira E, Rubio-Viqueira B, Strawn S, Wick MJ, Martell J, Sidransky D: A pilot clinical study of treatment guided by personalized tumorgrafts in patients with advanced cancer. Mol Cancer Ther 2011, 10:1311-1316.

46. Malaney P, Nicosia SV, Davé V: One mouse, one patient paradigm: New avatars of personalized cancer therapy. Cancer Lett 2014,

344:1-12.

47. Edgar R, Domrachev M, Lash AE: Gene Expression Omnibus: NCBI gene expression and hybridization array data repository. Nucleic Acids Res 2002, 30:207-210

48. TNBCtype, A Subtyping Tool for Triple-negative Breast Cancer. https://cbc.mc.vanderbilt.edu/tnbc.

49. Cohen AL, Soldi R, Zhang H, Gustafson AM, Wilcox R, Welm BE, Chang JT, Johnson E, Spira A, Jeffrey SS, Bild AH: A pharmacogenomic method for individualized prediction of drug sensitivity. Mol Syst Biol 2011, 7:513.

50. Lamb J, Crawford ED, Peck D, Modell JW, Blat IC, Wrobel MJ, Lerner J, Brunet JP, Subramanian A, Ross KN, Reich M, Hieronymus $H$, Wei G, Armstrong SA, Haggarty SJ, Clemons PA, Wei R, Carr SA, Lander ES, Golub TR: The Connectivity Map: using gene-expression signatures to connect small molecules, genes, and disease. Science 2006, 313:1929-1935.

51. Bild AH, Yao G, Chang JT, Wang Q, Potti A, Chasse D, Joshi MB, Harpole D, Lancaster JM, Berchuck A, Olson JA Jr, Marks JR, Dressman HK, West M, Nevins JR: Oncogenic pathway signatures in human cancers as a guide to targeted therapies. Nature 2006, 439:353-357.

52. Soldi R, Cohen AL, Cheng L, Sun Y, Moos PJ, Bild AH: A genomic approach to predict synergistic combinations for breast cancer treatment. Pharmacogenomics J 2013, 13:94-104.

53. University of Utah, Genetics Data Index. http://io.genetics.utah.edu.

54. Sørlie T, Perou CM, Tibshirani R, Aas T, Geisler S, Johnsen H, Hastie T, Eisen MB, van de Rijn M, Jeffrey SS, Thorsen T, Quist H, Matese JC, Brown PO, Botstein D, Lønning PE, Børresen-Dale AL: Gene expression patterns of breast carcinomas distinguish tumor subclasses with clinical implications. Proc Natl Acad Sci U S A 2001, 98:10869-10874.

55. Hu Z, Fan C, Oh DS, Marron JS, He X, Qaqish BF, Livasy C, Carey LA, Reynolds E, Dressler L, Nobel A, Parker J, Ewend MG, Sawyer LR, Wu J, Liu Y, Nanda R, Tretiakova M, Ruiz Orrico A, Dreher D, Palazzo JP, Perreard L, Nelson E, Mone M, Hansen H, Mullins M, Quackenbush JF, Ellis MJ, Olopade OI, Bernard PS, et al: The molecular portraits of breast tumors are conserved across microarray platforms. BMC Genomics 2006, 7:96.

56. Schneider CA, Rasband WS, Eliceiri KW: NIH Image to ImageJ: 25 years of image analysis. Nat Methods 2012, 9:671-675.

57. Marangoni E, Vincent-Salomon A, Auger N, Degeorges A, Assayag F, de Cremoux P, de Plater L, Guyader C, De Pinieux G, Judde JG, Rebucci M, Tran-Perennou C, Sastre-Garau X, Sigal-Zafrani B, Delattre O, Diéras V, Poupon MF: A new model of patient tumor-derived breast cancer xenografts for preclinical assays. Clin Cancer Res 2007, 13:3989-3998.

58. Cottu P, Marangoni E, Assayag F, de Cremoux P, Vincent-Salomon A, Guyader C, de Plater L, Elbaz C, Karboul N, Fontaine JJ, Chateau-Joubert S, BoudouRouquette P, Alran S, Dangles-Marie V, Gentien D, Poupon MF, Decaudin $D$ : Modeling of response to endocrine therapy in a panel of human 
luminal breast cancer xenografts. Breast Cancer Res Treat 2012, 133:595-606.

59. Valdez KE, Fan F, Smith W, Allred DC, Medina D, Behbod F: Human primary ductal carcinoma in situ (DCIS) subtype-specific pathology is preserved in a mouse intraductal (MIND) xenograft model. J Pathol 2011, 225:565-573.

60. Petrillo LA, Wolf DM, Kapoun AM, Wang NJ, Barczak A, Xiao Y, Korkaya H, Baehner F, Lewicki J, Wicha M, Park JW, Spellman PT, Gray JW, van't Veer L, Esserman $\sqcup$ : Xenografts faithfully recapitulate breast cancer-specific gene expression patterns of parent primary breast tumors. Breast Cancer Res Treat 2012, 135:913-922.

61. Reyal F, Guyader C, Decraene C, Lucchesi C, Auger N, Assayag F, De Plater L, Gentien D, Poupon MF, Cottu P, De Cremoux P, Gestraud P, Vincent-Salomon A, Fontaine JJ, Roman-Roman S, Delattre O, Decaudin D, Marangoni E: Molecular profiling of patient-derived breast cancer xenografts. Breast Cancer Res 2012, 14:R11.

62. DeRose $Y S$, Wang $G$, Lin $Y C$, Bernard PS, Buys SS, Ebbert MT, Factor R, Matsen C, Milash BA, Nelson E, Neumayer L, Randall RL, Stijleman IJ, Welm BE, Welm AL: Tumor grafts derived from women with breast cancer authentically reflect tumor pathology, growth, metastasis and disease outcomes. Nat Med 2011, 17:1514-1521.

63. Zhang X, Claerhout S, Prat A, Dobrolecki L, Petrovic I, Lai Q, Landis M, Wiechmann L, Schiff R, Giuliano M, Wong H, Fuqua S, Contreras A, Gutierrez C, Huang J, Mao S, Pavlick A, Froehlich AM, Wu MF, Tsimelzon A, Hilsenbeck SG, Chen E, Zuloaga P, Shaw C, Rimawi MF, Perou CM, Mills GB, Chang JC, Lewis MT: A renewable tissue resource of phenotypically stable, biologically and ethnically diverse, patient-derived human breast cancer xenografts. Cancer Res 2013, 73:4885-4897.

64. Ding L, Ellis MJ, Li S, Larson DE, Chen K, Wallis JW, Harris CC, McLellan MD, Fulton RS, Fulton LL, Abbott RM, Hoog J, Dooling DJ, Koboldt DC, Schmidt H, Kalicki J, Zhang Q, Chen L, Lin L, Wendl MC, McMichael JF, Magrini VJ, Cook L, McGrath SD, Vickery TL, Appelbaum E, Deschryver K, Davies S, Guintoli T, Lin L, et al: Genome remodelling in a basal-like breast cancer metastasis and xenograft. Nature 2010, 464:999-1005.

65. Kabos P, Finlay-Schultz J, Li C, Kline E, Finlayson C, Wisell J, Manuel CA, Edgerton SM, Harrell JC, Elias A, Sartorius CA: Patient-derived luminal breast cancer xenografts retain hormone receptor heterogeneity and help define unique estrogen-dependent gene signatures. Breast Cancer Res Treat 2012, 135:415-432.

66. Fiebig HH, Maier A, Burger AM: Clonogenic assay with established human tumour xenografts: correlation of in vitro to in vivo activity as a basis for anticancer drug discovery. Eur $J$ Cancer 2004, 40:802-820.

67. Stemke-Hale K, Gonzalez-Angulo AM, Lluch A, Neve RM, Kuo WL, Davies M, Carey M, Hu Z, Guan Y, Sahin A, Symmans WF, Pusztai L, Nolden LK, Horlings H, Berns K, Hung MC, van de Vijver MJ, Valero V, Gray JW, Bernards R, Mills GB, Hennessy BT: An integrative genomic and proteomic analysis of PIK3CA, PTEN, and AKT mutations in breast cancer. Cancer Res 2008, 68:6084-6091.

68. Smid M, Hoes M, Sieuwerts AM, Sleijfer S, Zhang Y, Wang Y, Foekens JA, Martens JW: Patterns and incidence of chromosomal instability and their prognostic relevance in breast cancer subtypes. Breast Cancer Res Treat 2011, 128:23-30.

69. Landis MD, Lehmann BD, Pietenpol JA, Chang JC: Patient-derived breast tumor xenografts facilitating personalized cancer therapy. Breast Cancer Res 2013, 15:201.

70. Moestue SA, Dam CG, Gorad SS, Kristian A, Bofin A, Maelandsmo GM, Engebraten O, Gribbestad IS, Bjorkoy G: Metabolic biomarkers for response to PI3K inhibition in basal-like breast cancer. Breast Cancer Res 2013, 15:R16.

71. Ellard SL, Clemons M, Gelmon KA, Norris B, Kennecke H, Chia S, Pritchard K, Eisen A, Vandenberg T, Taylor M, Sauerbrei E, Mishaeli M, Huntsman D, Walsh W, Olivo M, McIntosh L, Seymour L: Randomized phase II study comparing two schedules of everolimus in patients with recurrent/ metastatic breast cancer: NCIC Clinical Trials Group IND.163. J Clin Oncol 2009, 27:4536-4541.

72. Hart S, Novotny-Diermayr V, Goh KC, Williams M, Tan YC, Ong LC, Cheong A, Ng BK, Amalini C, Madan B, Nagaraj H, Jayaraman R, Pasha KM, Ethirajulu K, Chng WJ, Mustafa N, Goh BC, Benes C, McDermott U, Garnett M, Dymock B, Wood JM: VS-5584, a novel and highly selective PI3K/mTOR kinase inhibitor for the treatment of cancer. Mol Cancer Ther 2013, 12:151-161.

73. Guertin DA, Sabatini DM: The pharmacology of mTOR inhibition. Sci Signal 2009, 2:pe24.
74. Gökmen-Polar Y, Liu Y, Toroni RA, Sanders KL, Mehta R, Badve S, Rommel C, Sledge GW Jr: Investigational drug MLN0128, a novel TORC1/2 inhibitor, demonstrates potent oral antitumor activity in human breast cancer xenograft models. Breast Cancer Res Treat 2012, 136:673-682.

75. Feldman ME, Apsel B, Uotila A, Loewith R, Knight ZA, Ruggero D, Shokat KM: Active-site inhibitors of mTOR target rapamycin-resistant outputs of mTORC1 and mTORC2. PLOS Biol 2009, 7:e38.

76. Xu S, Li S, Guo Z, Luo J, Elllis MJ, Ma CX: Combined targeting of mTOR and AKT is an effective strategy for basal-like breast cancer in patient-derived xenograft models. Mol Cancer Ther 2013, 12:1665-1675.

doi: $10.1186 / \mathrm{bcr} 3640$

Cite this article as: Zhang et al: Patient-derived xenografts of triple-negative breast cancer reproduce molecular features of patient tumors and respond to mTOR inhibition. Breast Cancer Research 2014 16:R36.

\section{Submit your next manuscript to BioMed Central and take full advantage of:}

- Convenient online submission

- Thorough peer review

- No space constraints or color figure charges

- Immediate publication on acceptance

- Inclusion in PubMed, CAS, Scopus and Google Scholar

- Research which is freely available for redistribution

Submit your manuscript at www.biomedcentral.com/submit
() Biomed Central 